\title{
The Elevation-Dependence of Snowfall in the Appalachian Ridge and Valley Region of Northeastern Pennsylvania
}

\author{
MICHAEL EVANS \\ NOAA/NWS Binghamton, New York \\ MICHAEL JUREWICZ \\ NOAA/NWS Binghamton, New York \\ RACHAEL KLINE \\ State University of New York at Binghamton, New York
}

(Manuscript received 13 November 2016; review completed 26 March 2017)

\begin{abstract}
Northeastern Pennsylvania is located in the Appalachian Ridge and Valley region characterized by northeastsouthwest oriented ridges running parallel to broad valleys. Snowfall in the region can vary considerably over short distances owing to differences in elevation. To study the impact of elevation on snowfall in this region, a collection of snow events from 2005 to 2014 was studied. The median high-elevation versus low-elevation snowfall ratio - or orographic ratio-for the events was 1.27; however, several cases were identified that departed substantially from the average. The primary goal of this study is to give forecasters an understanding of factors that modulate the impact of elevation on snowfall in this region.

Nine events with a high-elevation dependency were compared to twelve events with a low-elevation dependency. High dependency was most likely with high-amplitude flow and deep surface cyclones along the East Coast, whereas low-dependency cases were associated with Miller type B cyclone tracks and flow that was less amplified. High-elevation dependency also was most likely for events with strong lower-tropospheric winds, along with surface temperatures $>-1^{\circ} \mathrm{C}\left(30^{\circ} \mathrm{F}\right)$ at Avoca, Pennsylvania. A relatively weak, inverse correlation was found between elevation dependence and lower-tropospheric stability. The Froude number is shown to be useful for determining the impact of elevation on snowfall. A regression equation was developed to help determine the impact of elevation on snowfall, and two case studies are shown to demonstrate that output from the equation can be used in conjunction with high-resolution model guidance to realistically assess the impact of elevation on snowfall in northeastern Pennsylvania.
\end{abstract}

\section{Introduction}

The Appalachian Ridge and Valley region of the eastern United States extends from southeastern New York to northeastern Alabama and is characterized by a series of long, northeast-southwest oriented, flattopped mountain ridges and broad valleys. Northeastern Pennsylvania is in the northeastern part of this region, with valleys approximately $5-15 \mathrm{~km}(3-10 \mathrm{mi})$ wide and ridge tops rising approximately $500 \mathrm{~m}$ (1640 ft) above the valleys (Fig. 1). The widest valley in the area extends in a northeast-southwest orientation along the Susquehanna River, and contains the city of Wilkes-Barre, Pennsylvania. Another significant valley is located along the Lackawanna River, which runs from northeast-southwest through some higher terrain northeast of Wilkes-Barre, before joining the Susquehanna Valley, approximately $15 \mathrm{~km}(10$ mi) northeast of Wilkes-Barre. The city of Scranton, Pennsylvania, is located within this valley. At the edge of the valleys the terrain rises steeply to ridges that run parallel to the rivers. Southeast and east of the ridge, adjacent to Wilkes-Barre, is the Pocono Plateau, with an average elevation around $600 \mathrm{~m}(2000 \mathrm{ft})$ above sea level (ASL).

The Scranton-Wilkes-Barre metropolitan area has 


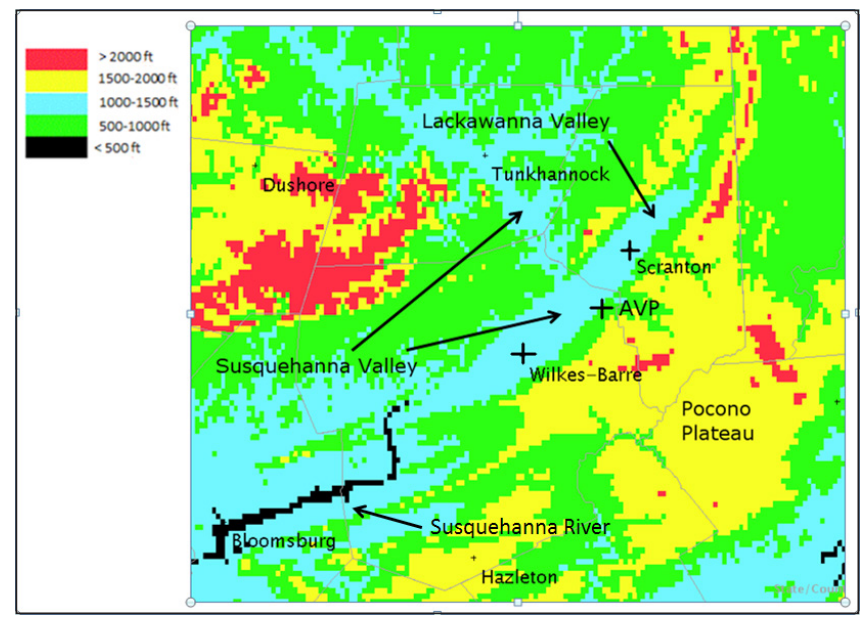

Figure 1. Topographical map of northeastern PA (shaded values represent $\mathrm{ft}$ ASL; multiply by 0.3048 to get $\mathrm{m})$. Click image for an external version; this applies to all tables and figures hereafter.

a population of approximately 550,000. Although the two largest cities in this region are located in valleys at elevations ranging from approximately 150 to 300 $\mathrm{m}$ (500 to $1000 \mathrm{ft}$ ) ASL, several significant towns, recreational sites, and interstate highway systems are located nearby, at higher elevations. The weather in this relatively small region can vary greatly over short distances owing to large differences in elevation, particularly during the winter when snowfall is often greater over higher elevations. For example, the average annual snowfall from 1981 to 2010 at the National Weather Service (NWS) cooperative observer (COOP) site at Shickshinny, Pennsylvania - at an elevation of $237 \mathrm{~m} \mathrm{(780} \mathrm{ft)-is} 89.2 \mathrm{~cm}$ (35.1 in), which is representative of the lowest elevations in the metro area, near the major rivers. The average annual snowfall at Wilkes-Barre/Scranton International Airport in Avoca, Pennsylvania (AVP) - at an elevation of $293 \mathrm{~m}(962$ $\mathrm{ft}$ ) - is $117.3 \mathrm{~cm}$ (46.2 in), which is representative of the middle elevation portions of the valley near the base of the ridges. The average annual snowfall at Pleasant Mount - at an elevation of $548 \mathrm{~m}(1799 \mathrm{ft})$ - is 174.0 $\mathrm{cm}$ (68.5 in), which is representative of many of the higher elevations around the area (Durre et al. 2012). All of these locations are within $50 \mathrm{~km}(30 \mathrm{mi})$ of the center of the Scranton-Wilkes-Barre metropolitan area. An examination of several winter storms affecting this area demonstrates that snowfall is typically greater at higher elevations than at lower elevations; however, there are times when this difference is extreme, but at other times the difference is not appreciable (Evans et al. 2012). As a result, forecasters tasked with predicting snowfall in this area continue to face challenges associated with large variations in snowfall over short distances. This issue is substantial not only in northeastern Pennsylvania, but all along the Appalachian Ridge and Valley region, where similar topography frequently interacts with winter storms. This paper discusses a study designed to aid forecasters faced with this challenge, with applicability not only for northeastern Pennsylvania, but all along the eastern slopes of the Appalachian Mountain chain.

Many studies associated with topographic influences on snowfall have been done over the western United States (e.g., Mass 1981; Steenburgh 2003; O'Hara et al. 2009; Alcott and Steenburgh 2013; Wesley et al. 2013). These studies have identified several key factors that act to enhance snowfall near and over higher terrain, such as orographic lift, stability, cold-air damming, and flow channeling. The topographic features described in these studies are generally more pronounced than the Appalachian ridges in the eastern United States; however, many of the factors identified in these studies likely play a role in precipitation patterns observed over the eastern United States.

The impacts of complex terrain on weather in the eastern United States were summarized by Keeter et al. (1995). Part of their summary included a discussion of cold-air damming, a phenomenon related to the interaction of the lower-tropospheric flow and stability with topography that has been shown to significantly impact precipitation patterns (Bell and Bosart 1988; Bosart and Dean 1991; Wesley et al. 2013). Studies performed by Perry et al. (2007) and Keighton et al. (2009) on enhancement of snowfall by terrain in northwesterly flow over the southern Appalachian mountains determined that orographic enhancement was increased in environments characterized by destabilization and enhanced moisture associated with an upstream flow connection with the Great Lakes. Last, a study on snowfall patterns in northern Vermont determined that the snowfall distribution in the Champlain Valley and nearby Green Mountains was affected when certain combinations of stability and wind promoted flow that was unable to ascend up and over the Green Mountains. This "blocked" flow typically resulted in the heaviest snowfalls shifting from the mountain crest to the western slopes of the mountains, and sometimes even farther upstream into the Champlain Valley (Muccilli 2015).

Muccilli (2015) also discussed the utility of the Froude number (Forbes et al. 1987; Chen et al. 2008) as a tool that can be used by forecasters to quantify 
blocking, and to anticipate the distribution of snowfall in the complex terrain of northern Vermont. Froude numbers $<1.0$ are associated with high topographic barriers, large stability, and/or winds with small components perpendicular to blocking topography, and are indicative of flow that can be blocked by the terrain. In blocked flow, substantial upslope or downslope wind components do not typically occur along the slopes of topographic barriers, and in some cases upslope flow may be offset from the barrier to an upstream valley. In this case, the usual tendency for the heaviest snowfall to occur near the top of the barrier is reduced. Values $>1.0$ are considered to be favorable for flow that is unblocked and flowing freely up and over mountain barriers. In these cases, one might expect more substantial upslope or downslope wind components along the slopes of the barrier, and potentially a larger dependence of precipitation and snowfall on elevation, with the largest amounts near the top of the barrier.

A case study of two rain events featuring topographically induced rain shadows in northeastern Pennsylvania examined the impact of topography, wind, and stability on the precipitation distribution in that area (Brady and Waldstreicher 2001). The results of that study reinforced previous findings that topography can have significant impacts on precipitation in the Appalachians under favorable atmospheric conditions. In those two rain events, the Froude number was determined to be 2.9 and 3.9, implying that boundary layer southeasterly winds should have been able to flow over the ridges and down into the valleys, with downslope flow reducing precipitation in the valleys - resulting in rain shadows. Another study on the impacts of wind and stability on snowfall in northeastern Pennsylvania, based on cases from 2005 to 2011, indicated that topographical enhancement of snowfall appeared to be favored in environments characterized by strong winds and large Froude numbers (Evans et al. 2012).

The study described in this paper is an extension of the work of Evans et al. (2012), with the following enhancements: 1) additional cases were added to their original dataset; 2) a more complete examination of atmospheric characteristics was done for each of the cases in the study; and 3) a more rigorous statistical evaluation of the results of the study was performed, including significance testing and the development of a regression equation to help predict the effect of elevation on snowfall. Section 2 in this paper summarizes the methods of the study. Results are shown in section 3, and two case studies are shown in section 4 . Section 5 contains a summary and discussion.

\section{Data and methods}

A collection of 94 snow events occurring in northeastern Pennsylvania from 2005 to 2014 was examined for the study. For each case, snowfall totals were derived by examination of reports from a variety of sources including the NWS contract observation at AVP, NWS COOP observations, the snow spotter network from the NWS Forecast Office at Binghamton, New York, and the Community Collaborative Rain, Hail, and Snow Network (Reges et al. 2016). The reports were confined to a region approximately 50 $\mathrm{km}$ in diameter centered on AVP (located midway between Wilkes-Barre and Scranton, Pennsylvania). This relatively small area was selected in an effort to ensure that variations in snowfall across the study area for a given event would be primarily due to elevation, as opposed to larger-scale gradients in precipitation amount or precipitation type.

After snowfall reports were compiled for each case, they were partitioned into reports from locations above $300 \mathrm{~m}$ (1000 ft) ASL (high-elevation locations), and locations below $300 \mathrm{~m}(1000 \mathrm{ft})$ ASL (low-elevation locations $)$. A value of $300 \mathrm{~m}(1000 \mathrm{ft})$ was chosen as a high-low elevation threshold after examination of topographic maps in the area indicated that the 300$\mathrm{m}(1000 \mathrm{ft})$ contour is typically in an area of steeply sloping terrain between river valleys and higher elevations; as such, most stations are located either at least $50 \mathrm{~m}$ (a few $100 \mathrm{ft}$ ) above $300 \mathrm{~m}$ (1000 ft) ASL on relatively flat terrain above the valleys, or $50 \mathrm{~m}$ (a few $100 \mathrm{ft}$ ) below, down in the valleys. Table 1 shows a list of the stations that were used in the study, along with their elevations. Exact elevations were available for AVP and the COOP stations used in the study. For the remainder of the reports, the elevation of the town center associated with the report was used to approximate the elevation of the location of the report. This method could have introduced a small error into the study, as there may have been some occasions when a report associated with a town was from a location far enough from the town center so that its elevation classification would be uncertain. However, there appeared to be enough reports with each storm so that this uncertainty would not substantially impact the snowfall distribution estimates. Based on this method, the average elevation for the seven "low-elevation" stations was $210 \mathrm{~m}(688$ $\mathrm{ft}) \mathrm{ASL}$, and the average elevation for the 18 "highelevation" stations was $488 \mathrm{~m}(1601 \mathrm{ft})$ ASL.

After this partitioning, a single high-elevation and single low-elevation snowfall total was derived for each 
Table 1. A list of the stations that were used in the study, along with their elevations. Values denoted with an $*$ indicate the elevation of the center of the listed town, which may be different than the location of the associated report.

\begin{tabular}{||l|l|l|}
\hline Station & Classification & Elevation (m; ft ASL) \\
\hline Wilkes-Barre / Scranton International Airport (AVP) & Low elevation & $293 ; 962$ \\
\hline Schickshinny 4.8 km (3 mi) north & Low elevation & $238 ; 780$ \\
\hline Exeter & Low elevation & $177 ; 580^{*}$ \\
\hline Pittston & Low elevation & $199 ; 653^{*}$ \\
\hline Scranton & Low elevation & $230 ; 754^{*}$ \\
\hline Swoyersville & Low elevation & $171 ; 560^{*}$ \\
\hline Wilkes-Barre & Low elevation & $160 ; 525^{*}$ \\
\hline Francis E Walter Dam & High elevation & $460 ; 1509$ \\
\hline Pleasant Mount 1.6 km (1 mi) west & High elevation & $548 ; 1799$ \\
\hline Bear Creek & High elevation & $464 ; 1522^{*}$ \\
\hline Beech Lake & High elevation & $400 ; 1312^{*}$ \\
\hline Clark's Summit & High elevation & $393 ; 1289^{*}$ \\
\hline Daleville & High elevation & $558 ; 1831^{*}$ \\
\hline Dallas & High elevation & $379 ; 1243^{*}$ \\
\hline Elmhurst & High elevation & $482 ; 1581^{*}$ \\
\hline Glenburne & High elevation & $355 ; 1165^{*}$ \\
\hline Gouldsboro & High elevation & $582 ; 1909^{*}$ \\
\hline Harvey's Lake & High elevation & $382 ; 1253^{*}$ \\
\hline Hazelton & High elevation & $571 ; 1873^{*}$ \\
\hline Moscow & High elevation & $525 ; 1722^{*}$ \\
\hline Mount Cobb & High elevation & $507 ; 1663^{*}$ \\
\hline Mountain Top & High elevation & $475 ; 1558^{*}$ \\
\hline Nescopeck pass & High elevation & $497 ; 1631^{*}$ \\
\hline Pocono Peak Lake & High elevation & $626 ; 2054^{*}$ \\
\hline Thornhurst & High elevation & $580 ; 1903^{*}$ \\
\hline & & \\
\hline Average low-elevation $=210 \mathrm{~m}(688 \mathrm{ft})$ & & \\
\hline Average high-elevation $=488 \mathrm{~m}(1601 \mathrm{ft})$ & & \\
\hline & & \\
\hline & & \\
\hline
\end{tabular}

storm, by averaging the reports from each group. The dataset of storms was then reduced so that only events with an average high- or low-elevation snowfall of $\geq 10 \mathrm{~cm}$ (4 in; the NWS threshold for a winter weather advisory in northeastern Pennsylvania during the period of study) were included. Finally, an event on 16 March 2007 was removed because data from AVP were missing for the storm. This process reduced the dataset to a total of 40 events. The surface cyclone track for each event was examined and classified as either Miller type A (storm track along the East Coast) or Miller type B (initial storm track over the Midwest with redevelopment off the East Coast; Miller 1946). Table 2 shows a list of each of these cases by date, along with the average high-elevation and low-elevation snowfall, orographic ratio, and Miller classification for each event.

For each of the 40 cases in the database, data were obtained at times when accumulating snow was occurring at AVP, as indicated by observations of snow with a visibility of $<3.2 \mathrm{~km}(2 \mathrm{mi})$ and the occurrence of measurable precipitation. Hourly surface temperatures and wind speeds at these times were averaged for each case. Surface wind speeds were obtained from wind gusts instead of the sustained wind (for times when gusts were reported). Additional upper-air data were obtained for each event by examining hourly forecast soundings (using the BUFKIT software; Mahoney and Niziol 1997) from the North American Mesoscale
(NAM) model (Rogers et al. 2001) initialized at times near the onset of the snow and valid at AVP. These data were mostly from 0 - to 12 -h forecasts. Data were time-averaged over the period of accumulating snow to determine single average values for each case.

The Froude number for each case was calculated at each hour over the period of accumulating snow, and then averaged to determine a single value for each case. The version of the Froude number equation was the same as in Brady and Waldstreicher (2001) and Muccilli (2015):

$$
\begin{aligned}
& \mathrm{Fr}=\mathrm{U} / \mathrm{NH}, \text { where } \\
& \mathrm{N}=\sqrt{ }((\mathrm{g} / \theta)(\partial \theta / \partial \mathrm{z})) .
\end{aligned}
$$

The variable $\mathrm{U}$ represents the component of the wind perpendicular to the terrain barrier, $\mathrm{N}$ is the Brunt-Väisälä frequency (a measure of stability), $\mathrm{H}$ is the height of the barrier; $g$ is gravity, and $\theta$ is potential temperature. For these calculations, the terrain barrier was assumed to be oriented from $210^{\circ}$ to $030^{\circ}$, with a height of $500 \mathrm{~m}$. The calculations were performed in the 0-1-km layer, which encompassed the layer from the surface to approximately $0.5 \mathrm{~km}$ above the ridge tops, and was representative of the lower troposphere.

Brady and Waldstreicher (2001) calculated the wind and stability components of the Froude number in the 975-925-hPa layer for their case studies, which was determined to be near ridge-top level for northeastern Pennsylvania. Muccilli (2015) calculated the stability component of the Froude number for the layer from the surface at Burlington, Vermont [approximately $91 \mathrm{~m}$ $(300 \mathrm{ft}) \mathrm{ASL}]$, to $1220 \mathrm{~m}(4000 \mathrm{ft}) \mathrm{ASL}$, or near the top of the Green Mountains. Mucilli used the wind at 1220 m (4000 ft) ASL for the wind component. In order to examine the sensitivity and utility of the Froude number to the time and layer selected for the calculations, Froude numbers in this study were determined not only at each hour in the $0-1-\mathrm{km}$ layer, but also at a time near the middle of the storm for both the $925-875-\mathrm{hPa}$ layer-which was generally at or just above the ridge tops - and for a layer extending from 152 to $457 \mathrm{~m}$ (500 to $1500 \mathrm{ft}$ ) above the surface elevation of the AVP forecast point, which would encompass the layer to just below ridge-top level.

The median ratio of high-elevation to low-elevation total snowfall [hereafter referred to as the "orographic ratio," following a convention introduced by Campbell et al. (2016) in a study on orographic impacts on lake effect snowfall] for all storms in the study was 1.27 
(Table 2). The first quartile of this ratio was 1.14 and the third quartile was 1.47. Based on these values, a lowelevation-dependence (LED) snow event was defined by a ratio of $\leq 1.15$, while a high-elevation-dependence (HED) event was defined by a ratio of $\geq 1.5$. A total of 12 events were defined as LED events, while nine events were defined as HED events. Characteristics of these 21 cases were compared and contrasted in order to determine factors that discriminate between low- and high-elevation dependence for snowfall.

Composite charts for the study were derived using the Earth System Research Laboratory web page (www. esrl.noaa.gov/psd/data/composites/hour/) that allows the user to create 6-h composites from the NCEP/ NCAR reanalysis (Kalnay et al. 1996). Times for each event were at 6 -h intervals $(0000,0600,1200$, or 1800 UTC), closest to the midpoint of the accumulating snow at AVP.

\section{Results \\ a. Snowfall}

Twelve of the cases in the dataset were classified as Miller type A events, while 28 of the cases were Miller type B (Table 2). The median low-elevation snowfall for the 40 cases was $11.9 \mathrm{~cm}$ (4.7 in), and the median high-elevation snowfall was $16.8 \mathrm{~cm}$ (6.6 in; Table 2). The median low-elevation snowfall for the nine HED cases was $8.4 \mathrm{~cm}$ (3.3 in), and the median high-elevation snowfall for those cases was $21.6 \mathrm{~cm}$ (8.5 in). The median low-elevation snowfall for the 12 LED cases was $16.5 \mathrm{~cm}$ (6.5 in), and the median highelevation snowfall for those cases was $16.8 \mathrm{~cm}$ (6.6 in). The orographic ratio in the Scranton-Wilkes-Barre metropolitan area during the period of study ranged from a minimum of 0.91 to a maximum of 21.54. Six out of 40 events exhibited a ratio $>2.0$, while two of 40 exhibited a ratio $<1.0$. The median ratio was 1.27 , and the mean was 1.88 . For each storm, the high- and low-elevation snowfall totals were averaged to derive an all-elevation average. No significant relationship was found between elevation dependence ratio and allelevation average.

\section{b. Seasonal patterns}

The peak of the cold season (December-February) contained 31 of the 40 events in the study, with a median orographic ratio for those cases of 1.24. The median ratio for the nine events that occurred during the off-season (October-November and March-April) was
Table 2. Date and snowfall for the 40 cases in the study, with average high- or low-elevation snowfall of $\geq 10.2 \mathrm{~cm}$ (4 in), and the orographic ratio. LED cases are highlighted in bold font. HED cases are highlighted using italics.

\begin{tabular}{|c|c|c|c|c|c|}
\hline Date & Time & $\begin{array}{l}\text { Low- } \\
\text { elevation } \\
\text { average }(\mathrm{cm} \text {; } \\
\text { in) }\end{array}$ & $\begin{array}{l}\text { High-elevation } \\
\text { average }(\mathrm{cm} \text {; in) }\end{array}$ & $\begin{array}{l}\text { Orographic } \\
\text { Ratio }\end{array}$ & $\begin{array}{l}\text { Miller } \\
\text { Classification }\end{array}$ \\
\hline 5-6 Jan 2005 & $2200-0600$ UTC & $10.2 ; 4.0$ & $12.5 ; 4.9$ & 1.24 & B \\
\hline $23 \operatorname{Jan} 232005$ & $0200-1200$ UTC & $22.4 ; 8.8$ & $26.9 ; 10.6$ & 1.21 & B \\
\hline $21 \mathrm{Feb} 2005$ & $0100-0700$ UTC & $10.2 ; 4.0$ & $13.5 ; 5.3$ & 1.33 & B \\
\hline 01 Mar 2005 & $0000-0800$ UTC & $17.5 ; 6.9$ & $24.1 ; 9.5$ & 1.39 & B \\
\hline $23 \mathrm{Mar} 2005$ & $1900-2400$ UTC & $17.8 ; 7.0$ & $21.1 ; 8.3$ & 1.19 & B \\
\hline 09 Dec 2005 & 0500-1400 UTC & $20.6 ; 8.1$ & $23.6 ; 9.3$ & 1.15 & B \\
\hline 14 Feb 2007 & $1500-2200$ UTC & $34.3 ; 13.5$ & $37.3 ; 14.7$ & 1.08 & B \\
\hline $16 \mathrm{Apr}, 2007$ & $1200-2400$ UTC & $14.5 ; 5.7$ & $33.8 ; 13.2$ & 2.33 & $A$ \\
\hline 18 Nov 2007 & $1800-2400$ UTC & $10.2 ; 4.0$ & $21.6 ; 8.5$ & 2.16 & $B$ \\
\hline 13 Dec 2007 & $1100-1500$ UTC & $12.5 ; 4.9$ & $15.5 ; 6.1$ & 1.26 & B \\
\hline 31 Dec 2007 & \begin{tabular}{|l|}
$0300-0800$ UTC \\
\end{tabular} & $11.7 ; 4.6$ & $13.0 ; 5.1$ & 1.12 & B \\
\hline $22 \mathrm{Feb} 2008$ & $1500-1800$ UTC & $11.9 ; 4.7$ & $17.8 ; 7.0$ & 1.47 & B \\
\hline 28 Oct 2008 & $1600-1800$ UTC & $1.3 ; 0.5$ & $27.4 ; 10.8$ & 21.54 & $A$ \\
\hline 19 Dec 2008 & 1400-1900 UTC & $19.1 ; 7.5$ & \begin{tabular}{|l|}
$19.8 ; 7.8$ \\
\end{tabular} & 1.05 & B \\
\hline 10 Jan 2009 & $1500-2400$ UTC & $3.7 ; 9.4$ & $4.0 ; 10.2$ & 1.08 & B \\
\hline $18 \operatorname{Jan} 2009$ & $0600-0900$ UTC & $5.6 ; 2.2$ & $12.2 ; 4.8$ & 2.25 & $B$ \\
\hline $28 \operatorname{San} 2009$ & 0600-1300 UTC & $6.6 ; 2.6$ & $10.9 ; 4.3$ & 1.65 & $B$ \\
\hline 5 Dec 2009 & 1700-2300 UTC & $10.9 ; 4.3$ & $12.4 ; 4.9$ & 1.14 & $\mathbf{A}$ \\
\hline 9 Dec 2009 & 0400-0900 UTC & $8.4 ; 3.3$ & $17.0 ; 6.7$ & 2.02 & $B$ \\
\hline $10 \mathrm{Feb} 2010$ & $1200-2300$ UTC & $19.6 ; 7.7$ & $25.4 ; 10.0$ & 1.30 & B \\
\hline $25-26 \mathrm{Feb} 2010$ & $1200-1200$ UTC & $28.7 ; 11.3$ & $49.8 ; 19.6$ & 1.73 & $A$ \\
\hline 27 Dec 2010 & $0300-1100$ UTC & $9.1 ; 3.6$ & $5.1 ; 13.0$ & 1.42 & A \\
\hline 12 Jan 2011 & \begin{tabular}{|l|}
$0100-0900$ UTC \\
\end{tabular} & $13.2 ; 5.2$ & $13.5 ; 5.3$ & 1.02 & B \\
\hline 21 Jan 2011 & \begin{tabular}{|l|}
$0200-0900$ UTC \\
\end{tabular} & $10.9 ; 4.3$ & $10.9 ; 4.3$ & 1.01 & B \\
\hline $01 \mathrm{Feb} 2011$ & $0800-1600$ UTC & $10.4 ; 4.1$ & $13.2 ; 5.2$ & 1.28 & B \\
\hline 21 Feb 2011 & \begin{tabular}{|l}
$0400-1300$ UTC \\
\end{tabular} & $21.6 ; 8.5$ & $19.6 ; 7.7$ & 0.91 & B \\
\hline 07 Mar 2011 & $0700-1200$ UTC & $10.9 ; 4.3$ & $13.2 ; 5.2$ & 1.20 & A \\
\hline 23 Mar 2011 & 0400-1200 UTC & $22.4 ; 8.8$ & $21.6 ; 8.5$ & 0.97 & B \\
\hline 29 Oct 2011 & $1500-2200$ UTC & $11.9 ; 4.7$ & $26.4 ; 10.4$ & 2.21 & $A$ \\
\hline $21 \mathrm{Jan} 2012$ & $0600-1500$ UTC & $10.9 ; 4.3$ & $12.7 ; 5.0$ & 1.17 & B \\
\hline $26 \operatorname{Dec} 2012$ & $1800-2400$ UTC & $8.4 ; 3.3$ & $13.7 ; 5.4$ & 1.65 & $A$ \\
\hline $29 \operatorname{Dec} 2012$ & $1500-2100$ UTC & $11.9 ; 4.7$ & $14.0 ; 5.5$ & 1.18 & B \\
\hline 16 Jan 2013 & $0600-1200$ UTC & $7.8 ; 3.1$ & $11.7 ; 4.6$ & 1.48 & A \\
\hline 08 Feb 2013 & $2100-0600$ UTC & $14.0 ; 5.5$ & $15.0 ; 5.9$ & 1.08 & B \\
\hline 14-15 Dec 2013 & $1800-0400$ UTC & $13.0 ; 5.1$ & $17.0 ; 6.7$ & 1.32 & B \\
\hline 2-3 Jan 2014 & $2000-0900$ UTC & $13.5 ; 5.3$ & $16.5 ; 6.5$ & 1.24 & B \\
\hline 05 Feb 2014 & 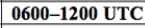 & $20.8 ; 8.2$ & \begin{tabular}{|l|}
$23.1 ; 9.1$ \\
\end{tabular} & 1.10 & B \\
\hline $13-14$ Feb 2014 & $1300-0700$ UTC & $25.7 ; 10.1$ & $35.1 ; 13.8$ & 1.37 & A \\
\hline $26-27$ Nov 2014 & $1300-0300$ UTC & $14.5 ; 5.7$ & $20.8 ; 8.2$ & 1.45 & A \\
\hline 11 Dec 2014 & $0400-0900$ UTC & $7.4 ; 2.9$ & $10.9 ; 4.3$ & 1.47 & A \\
\hline Median & & $11.9 ; 4.7$ & $16.8 ; 6.6$ & 1.27 & \\
\hline
\end{tabular}

1.45 , indicating that elevation impacts snowfall more in the off-season than during the peak of the cold season. Based on a threshold ratio of $\leq 1.15$ for an LED event, 11 of 31 peak-season events were LED events (35\%), while one of the nine off-season events was an LED event $(11 \%)$. Based on a threshold ratio of $\geq 1.5$ for an HED event, five of 31 peak season events were HED $(16 \%)$, while four of nine off-season events were HED $(44 \%)$.

\section{c. Flow pattern factors determining elevation dependence}

A comparison of the mean $500-\mathrm{hPa}$ height pattern associated with HED versus LED events is shown in Fig. 2. Both composites indicate upper-level trough placement near the East Coast; however, the mean trough associated with the HED cases is deeper and located farther east, and the downstream ridge is more amplified. The 500-hPa geopotential height patterns associated with individual cases indicate a tendency for 

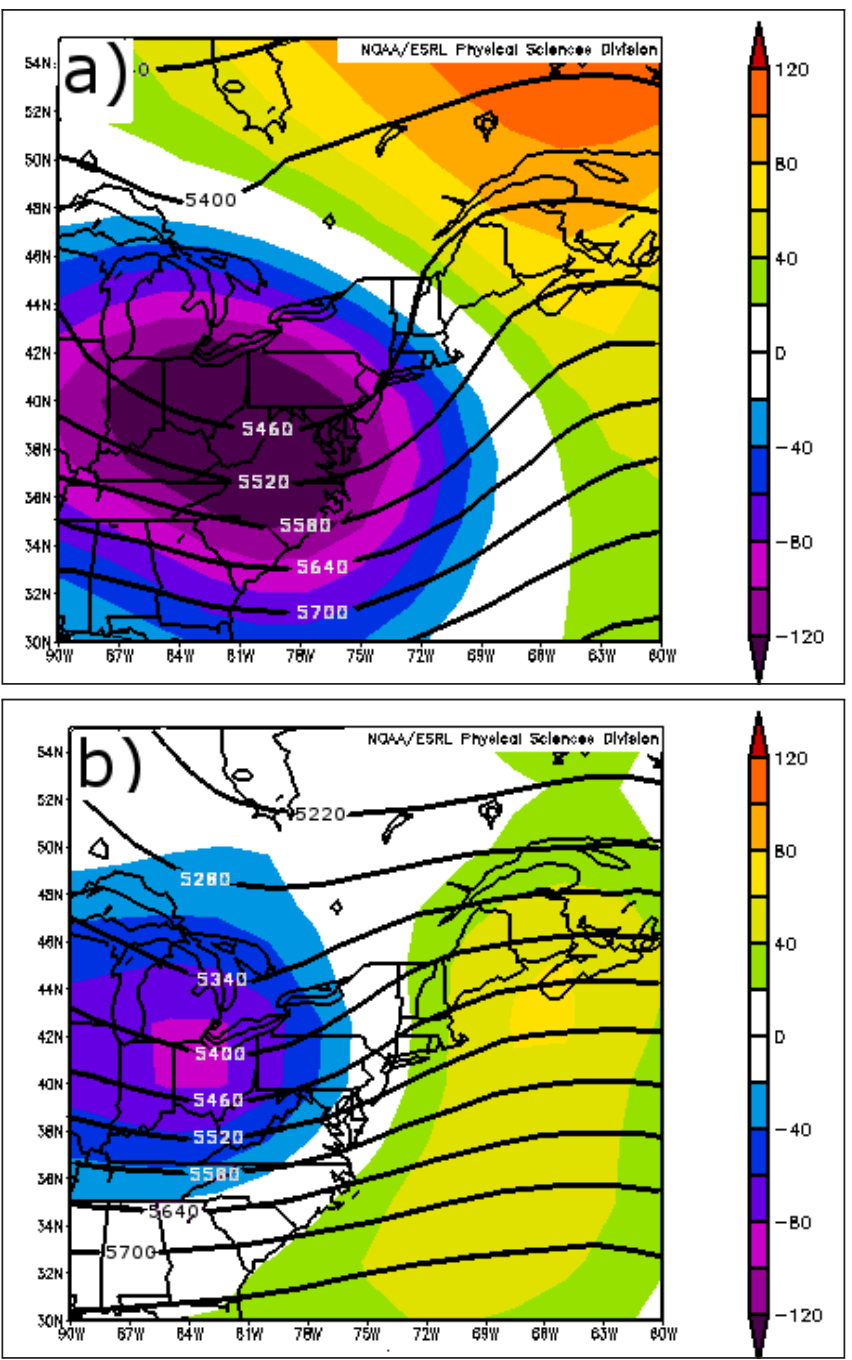

Figure 2. Composite $500-\mathrm{hPa}$ heights (m) for the a) high-elevation dependence cases and b) low-elevation dependence cases in the study. Shaded values are height anomalies (m).

more closed lows in the HED events (based on analysis using a 60-m contour interval); five of nine HED cases were associated with a closed-contour low center, while three of 12 LED cases were associated with a closedcontour low center.

Composite sea-level pressure charts (Fig. 3) indicate surface low pressure along the East Coast for both types; however, the surface low is deeper and closer to the coast for the HED cases. Both types are associated with surface high pressure over eastern and central Canada; however, the high pressure area is centered much farther east for the HED cases. Examination of surface cyclone tracks associated with individual cases indicates that five of nine HED cases were Miller type A events, while LED cases were almost exclusively classified as Miller type B (11 of the 12 cases).

Values of several parameters at the AVP observation site compared for HED cases versus LED cases are shown in Figs. 4-6. Data for surface temperature at the AVP observation site (time-averaged over the duration of the snowfall) indicate that HED events typically occur with higher temperatures, although substantial overlap is indicated between the two categories (Fig. 4). Despite the overlap, further examination of the data indicates that the surface temperature may still be a valuable indicator of elevation dependence; for example, only one LED case occurred with a surface temperature at AVP greater than $-1^{\circ} \mathrm{C}\left(30^{\circ} \mathrm{F}\right)$, while 5 of the 9 HED events occurred with surface temperatures at AVP greater than $-1^{\circ} \mathrm{C}\left(30^{\circ} \mathrm{F}\right)$.

Less overlap is indicated for the time-averaged
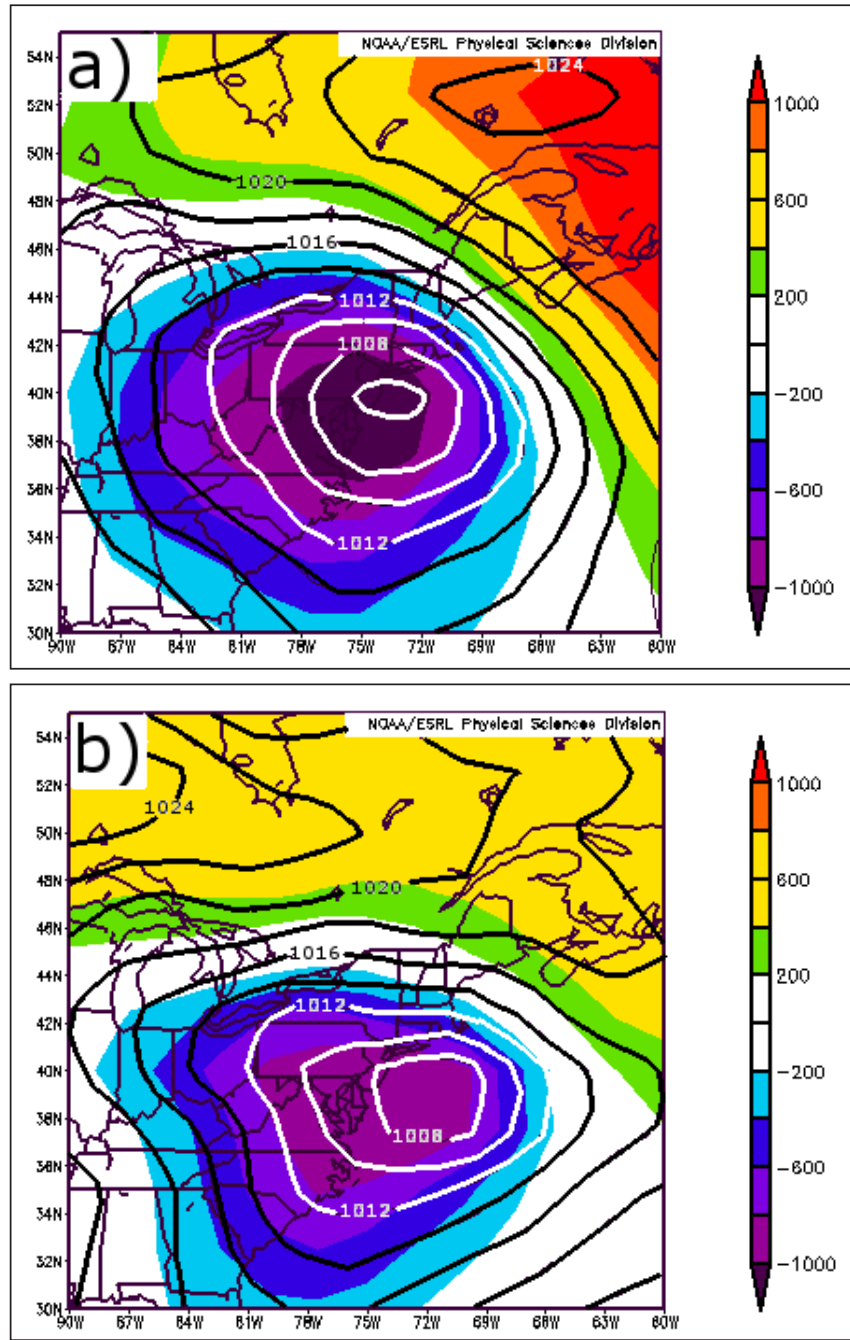

Figure 3. Composite sea-level pressure $(\mathrm{hPa})$ for the a) high-elevation dependence cases and b) low-elevation dependence cases in the study. Shaded values are sealevel pressure anomalies $(\mathrm{Pa})$. 


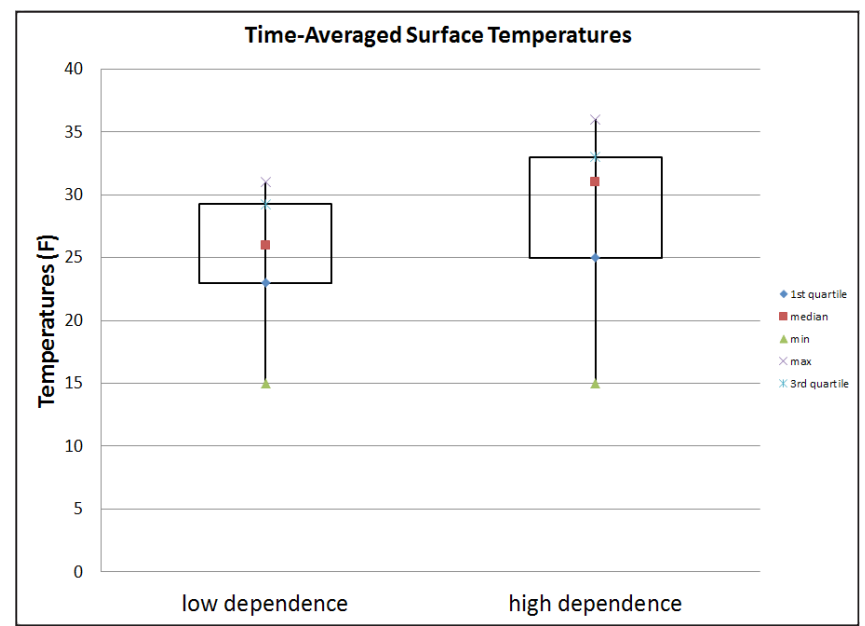

Figure 4. Box and whiskers plots of time-averaged observed surface temperatures $\left[{ }^{\circ} \mathrm{F} ;{ }^{\circ} \mathrm{C}=\left({ }^{\circ} \mathrm{F}-32\right) / 1.8\right]$ at AVP for the low-elevation and high-elevation dependence events in the study.

surface wind speeds, with an implied threshold of 2.6 $\mathrm{m} \mathrm{s}^{-1}$ (5 kt) for high dependence (Fig. 5a). The timeaveraged values of the NAM-forecast component of the $0-1-\mathrm{km}$ mean wind perpendicular to a $210^{\circ}$ to $030^{\circ}$ oriented ridge barrier at AVP also imply a clear threshold for high dependence versus low dependence, with a value of around $6 \mathrm{~m} \mathrm{~s}^{-1}$ (12 kt, Fig. 5b). Data for other variations of lower-tropospheric wind also indicated that wind speed was an excellent discriminator between high- and low-elevation dependence for the cases in this study.

Time-averaged values of NAM-forecast 950-850$\mathrm{hPa}$ lapse rates at AVP indicated slightly more unstable conditions with HED events, but also a substantial overlap with LED events. In order to test for the possibility that the model forecasts were not accurately depicting the lower-tropospheric lapse rate, the ratio of the time-averaged observed surface wind and the timeaveraged $0-1-\mathrm{km}$ wind was tested for each case, with the hypothesis being that unstable conditions would be associated with a well-mixed environment and a ratio near 1.0, while stable conditions would be associated with lighter winds at the surface compared to aloft, and a relatively lower ratio. Results indicate that the highdependence events were slightly more well mixed than the low-elevation events, but similar to the calculations of lapse rate there was substantial overlap between the two categories. Similar results also occurred when the Brunt-Väisälä frequency was tested; the median was slightly larger (more stable) for LED cases than for HED cases, but with a large overlap (not shown).
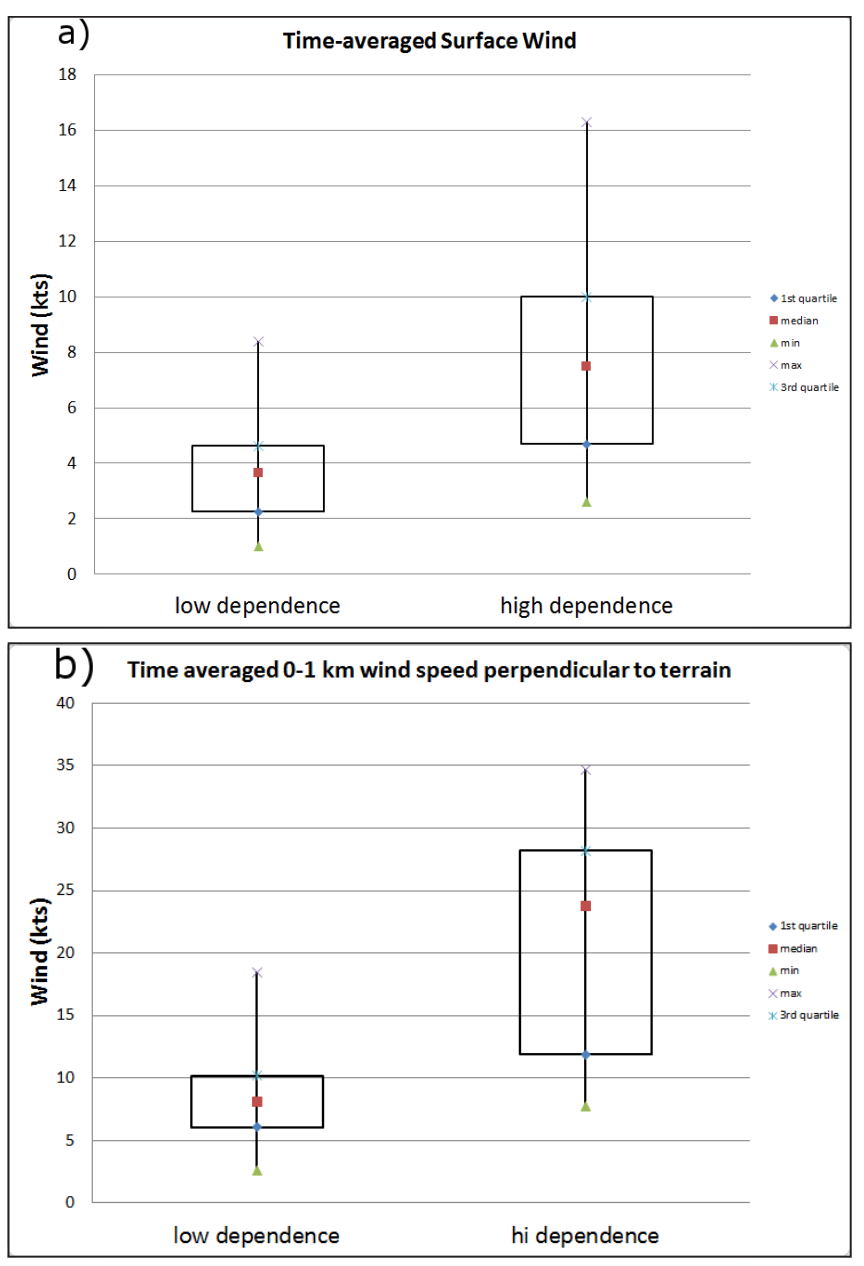

Figure 5. Box and whiskers plots of a) time-averaged observed surface wind ( $\mathrm{kt}$; multiply by 0.5144 for $\mathrm{m}$ $\mathrm{s}^{-1}$ ) at AVP for the low-elevation and high-elevation dependence events in the study and b) time-averaged NAM-forecast $0-1-\mathrm{km}$ wind speed component perpendicular to the terrain for the low-elevation and high-elevation dependence events in the study.

A comparison of the time-averaged Froude numbers calculated for $0-1 \mathrm{~km}$ for HED versus LED cases indicated higher values for HED cases, with an implied threshold near 1.0 (Fig. 6a). This confirmed the work from Muccilli (2015) that the Froude number can be a valuable tool to quantify elevation impacts on precipitation and snowfall. Froude numbers calculated at a single time during the middle of the storm for the HED and LED cases over layers from 152 to $457 \mathrm{~m}$ (500 to $1500 \mathrm{ft}$ ) ASL and 875 to $925 \mathrm{hPa}$ (Fig. 6b) gave similar results, indicating that the utility of the Froude number does not appear to be overly sensitive to what time or layer is selected for the calculation.

Table 3 lists the correlation coefficient between 

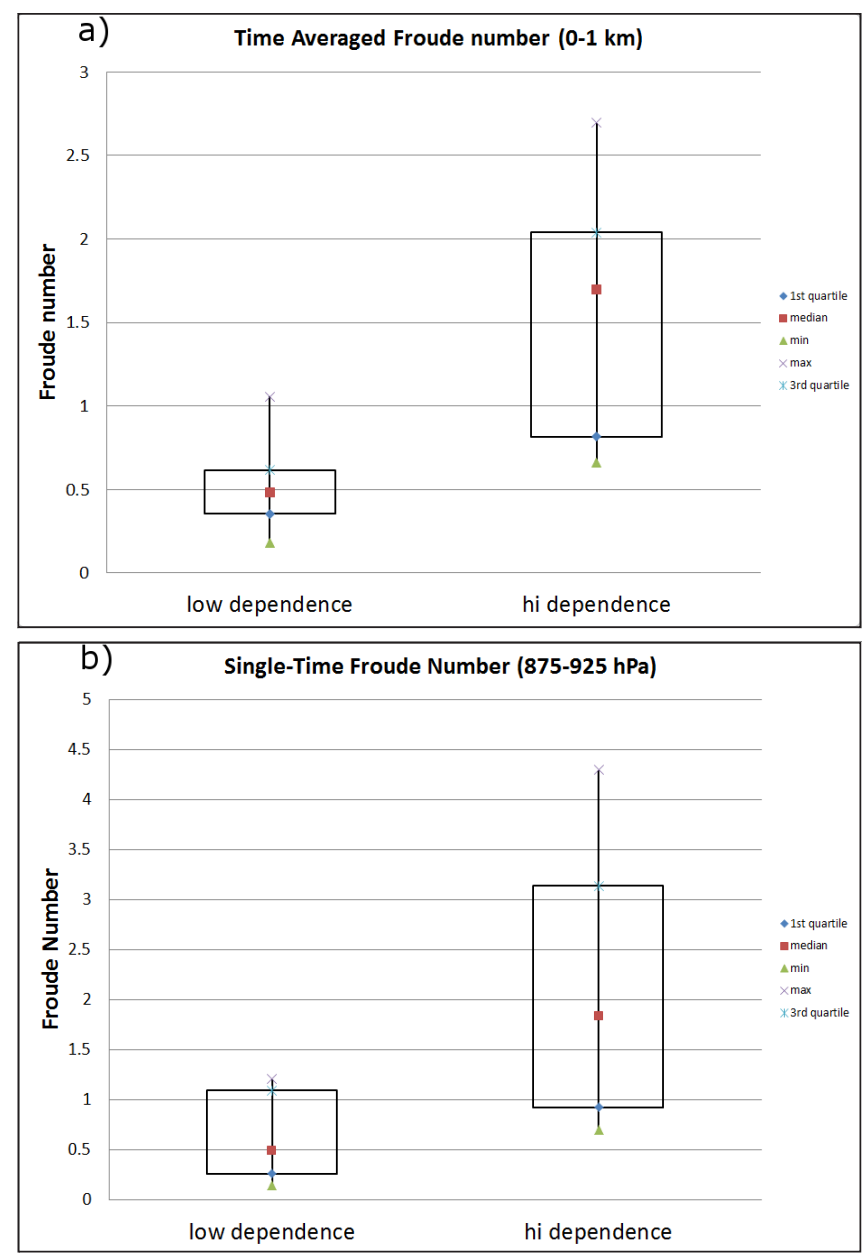

Figure 6. Box and whiskers plots of a) the time-averaged Froude number calculated from NAM forecasts for the 0-1-km layer at AVP . b) Same as a), except that the Froude number was calculated at a single time during the midpoint of the storm for the 875-925-hPa layer.

several parameters and the observed orographic ratio for 39 events in the study (one outlier case with a ratio of 21.54 was removed for this analysis). A comparison between these correlations and a critical value of 0.30 based on a two-tailed test with a 5\% significance level indicated that the correlation with orographic ratio was significant for both the $0-1-\mathrm{km}$ wind and Froude number, but not for the other parameters in the study. The significance of the difference between values of several parameters in the LED versus the HED dataset also was tested at the 5\% significance level (using a Wilcox test for the alternate hypothesis that the parameter values from one dataset were higher than the values from the other dataset) based on their numerical ranks (Gibbons 1976). This test also indicated a significant difference between values of the $0-1-\mathrm{km}$ wind and Froude number between the two datasets, while differences between values of other parameters were not significant.

The data from this study indicate that wind speed and direction appear to be critical for determining HED versus LED in the ridge and valley region of northeastern Pennsylvania. Figure 7 summarizes the relationship between the $0-1-\mathrm{km}$ time-averaged wind speed and direction and the snowfall ratio for the 21 HED/LED cases in the study. LED events are clustered from south to northeast at speeds of $\leq 7.7 \mathrm{~m} \mathrm{~s}^{-1}$ (15 kt). The HED events are mostly plotted with speeds of $>7.7$ $\mathrm{m} \mathrm{s}^{-1}(15 \mathrm{kt})$. There appear to be two favored directions one from the south through east with a second cluster from the northwest. Both of these directions indicate flow with a substantial component perpendicular the southwest-northeast oriented ridges in the area.

\section{d. Development of a regression equation}

Regression models are used in an attempt to describe the relationship between variables. Here, a multiple linear regression (MLR) model is developed with the orographic ratio as the predicted variable. A general equation for an MLR model is $Y=\beta_{0}+\sum_{\mathrm{i}=1}^{\mathrm{p}}\left(\beta_{i} x_{i}\right)$ $+\varepsilon$ where $\mathrm{Y}$ is the dependent predicted variable, the $x_{i}$ 's represent $p$ independent explanatory variables with the corresponding coefficients $\beta_{i}$, and $\varepsilon$ is the random error term assumed to be normally distributed with a mean of zero and a constant variance. The model is derived by fitting the dataset with 40 observations and 10 potential explanatory factors in the statistical software R (www.R-

Table 3. Pearson correlation coefficients between several parameters and the high-elevation versus lowelevation snowfall ratio for 39 cases in the study with one outlier removed. Values in bold font were determined to be significant at the $5 \%$ confidence level. The results of the Wilcox test for significant difference in values between the LED and HED datasets is in the right column. The relationship between these parameters and the regression equation from section $3 d$ is denoted in the parameter column.

\begin{tabular}{|l|c|c|}
\hline Parameter & $\begin{array}{c}\text { Correlation with high- } \\
\text { versus low-elevation } \\
\text { snowfall ratio }\end{array}$ & $\begin{array}{c}\text { Significant } \\
\text { difference in } \\
\text { LED versus } \\
\text { HED datasets }\end{array}$ \\
\hline Time-averaged surface temperature $\left(\mathrm{x}_{1}\right)$ & 0.22 & No \\
\hline Time-averaged surface wind speed $\left(\mathrm{x}_{2}\right)$ & 0.12 & No \\
\hline Time-averaged Froude number $(\mathbf{0}-\mathbf{1} \mathbf{~ k m})$ & $\mathbf{0 . 4 6}$ & Yes \\
\hline Froude number at a single time $(\mathbf{8 7 5}-\mathbf{9 2 5} \mathbf{h P a})$ & $\mathbf{0 . 4 2}$ & Yes \\
\hline Time-averaged 0-1-km wind speed $\left(\mathbf{x}_{3}\right)$ & $\mathbf{0 . 3 9}$ & Yes \\
\hline Time-averaged 0-1-km Brunt-Väisälä frequency $\left(\mathrm{x}_{5}\right)$ & -0.22 & No \\
\hline Time-averaged $900-\mathrm{hPa}$ temperature & 0.11 & No \\
\hline Time-averaged 0-1-km wind speed $\left(\mathbf{x}_{2}\right)$ & $\mathbf{0 . 4 5}$ & Yes \\
\hline Time-averaged $950-850-\mathrm{hPa}$ lapse rate & 0.20 & No \\
\hline Time-averaged surface / 0-1-km wind speed $\left(\mathrm{x}_{4}\right)$ & -0.07 & No \\
\hline
\end{tabular}




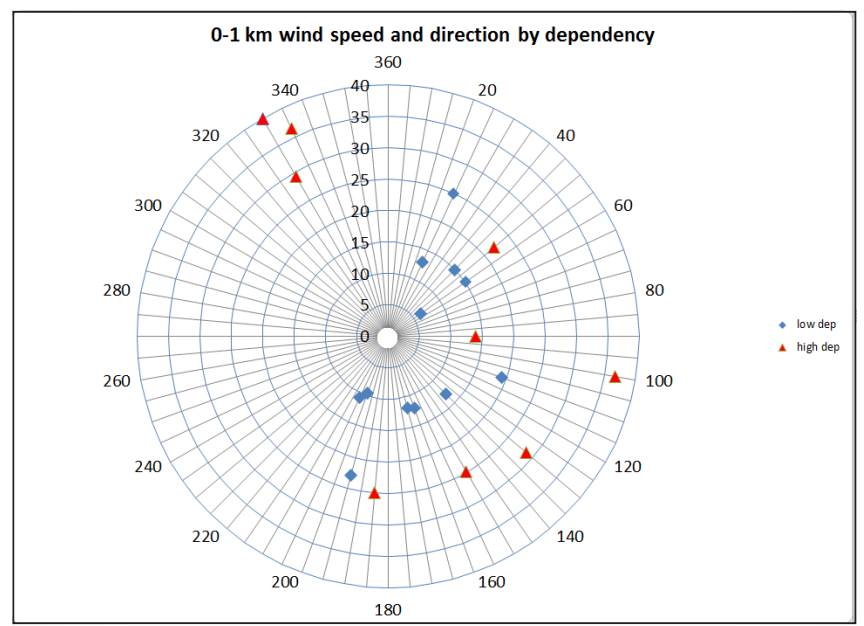

Figure 7. Time-averaged NAM forecast $0-1-\mathrm{km}$ wind speed (kt; multiply by 0.5144 for $\mathrm{m} \mathrm{s}^{-1}$ ) and direction $\left({ }^{\circ}\right)$ for the low-elevation dependence and high-elevation dependence cases in the study.

project.org/). The initial 10 potential explanatory factors included time-averaged surface wind and temperature, $900-\mathrm{hPa}$ temperature, three parameters related to stability, three parameters related to lower-tropospheric wind speed, and a version of the Froude number. One case on 28 October 2008 with a ratio of 21.54 was an outlier for this dataset and was thus removed (reducing the dataset to 39 cases). In addition, it was decided that in order to ensure that the model would be operationally intuitive, at least one parameter should be related to temperature, at least one parameter should be related to stability, and at least one parameter should be related to wind speed. Variance inflation factors were calculated as a metric to measure how much inflation is in a given factor's coefficient, owing to the presence of other correlated factors. These were used to assist in choosing which factors were removed. An analysis of variance $F$ test was performed at each step of removing factors to ensure the removal was justified statistically. Additional tests and plots were used to ensure that the appropriate assumptions of the model were met. The proposed model is

$$
\begin{aligned}
& Y=0.4804+0.0105 \times 1-0.09315 \times 2+0.0602 \times 3 \\
& +1.7896 \times 4-32.1653 \times 5, \quad(3)
\end{aligned}
$$

where $\mathrm{Y}$ is the orographic ratio, $\mathrm{x} 1$ is the time-averaged surface temperature at AVP, $\mathrm{x} 2$ is the time-averaged surface wind speed at AVP, $\mathrm{x} 3$ is the time-averaged $0-1$ $\mathrm{km}$ wind speed at AVP, $\mathrm{x} 4$ is the time-averaged ratio of the surface wind versus the $0-1-\mathrm{km}$ wind at AVP,

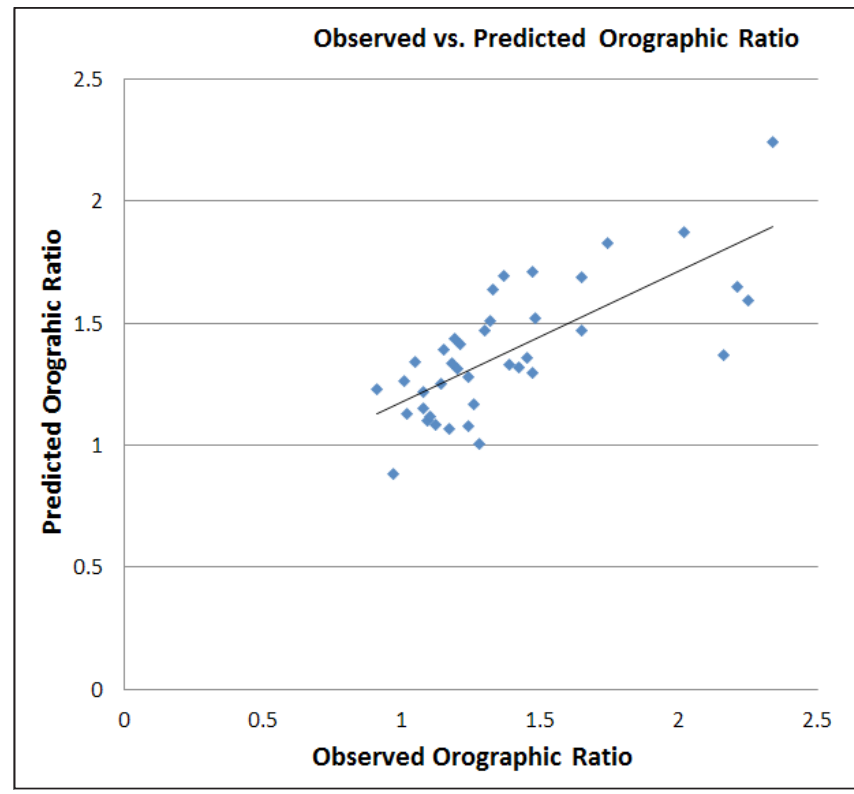

Figure 8. Time-averaged NAM forecast $0-1-\mathrm{km}$ wind speed (kt; multiply by 0.5144 for $\mathrm{m} \mathrm{s}^{-1}$ ) and direction $\left({ }^{\circ}\right)$ for the low-elevation dependence and high-elevation dependence cases in the study.

and $x 5$ is the Brunt-Väisälä frequency from Eq. (2). $R^{2}$ for this model is $0.53 ; \mathrm{R}^{2}$ is a metric that measures the percentage of variance explained, and a value close to 1 indicates a good fit.

Figure 8 shows a scatter diagram of the observed orographic ratio for the cases in the study versus the orographic ratio predicted by the regression equation.

\section{Case studies}

Two case studies are shown in this section to illustrate the potential utility of the regression equation. These cases were two of the largest snow events that affected northeastern Pennsylvania in 2015, which was the first year after the period of data collection ended in 2014.

\section{January 2015}

A surface low pressure developed along the midAtlantic coast during the morning of 24 January 2015 as a midlevel trough tracked east across the Tennessee Valley (Fig. 9). Mean snowfall forecasts from the 1200 UTC 23 January 2015 run of the Storm Prediction Center's (SPC) high-resolution Storm Scale Ensemble of Opportunity (SSEO, model grid spacing of 3-4 km, Jirak et al. 2012) valid at 1200 UTC 24 January were 

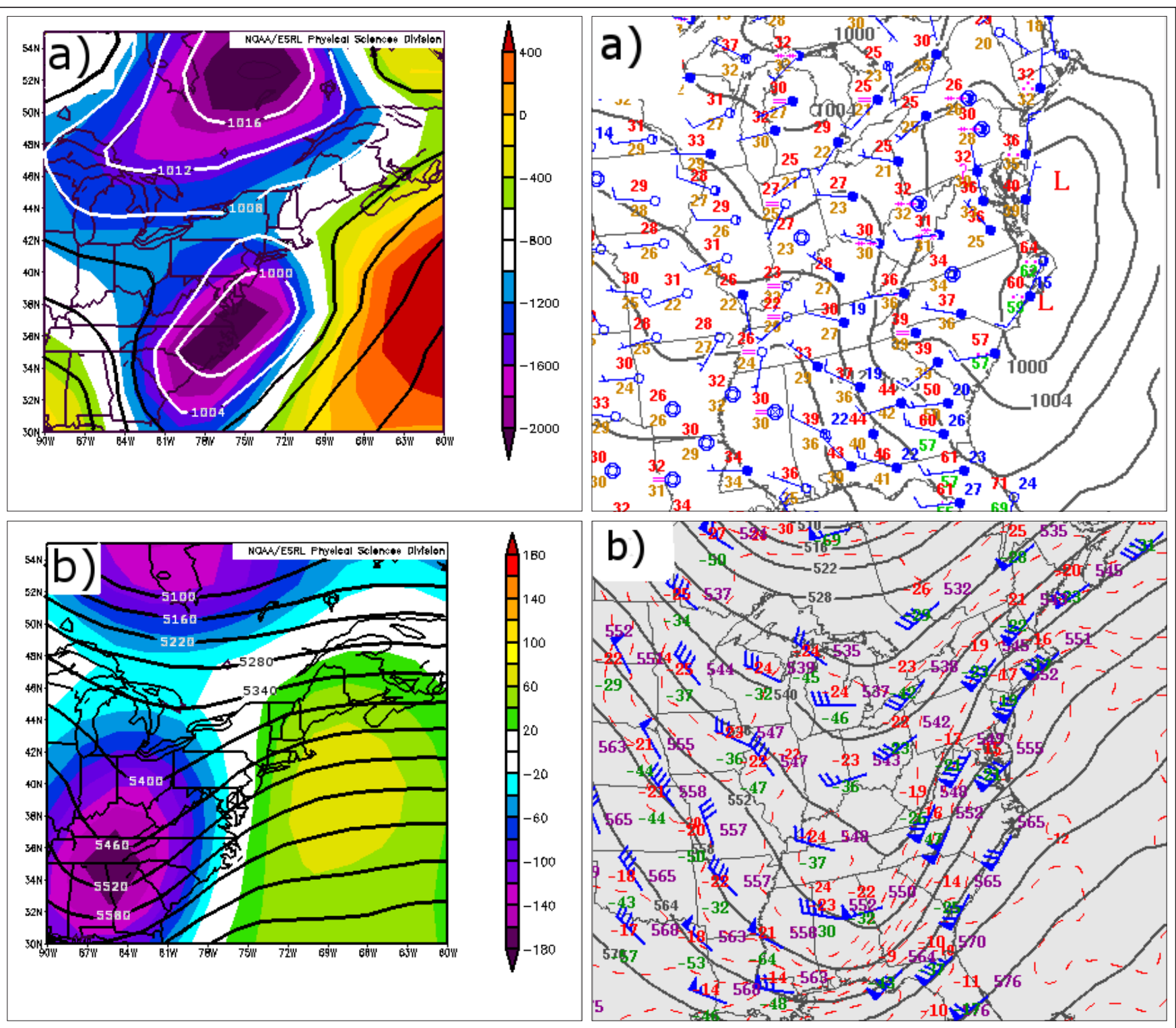

Figure 9. a) Sea-level pressure (hPa, solid contours) and surface plot $\left[{ }^{\circ} \mathrm{F} ;{ }^{\circ} \mathrm{C}=\left({ }^{\circ} \mathrm{F}-32\right) / 1.8\right]$ at 1200 UTC 24 January 2015. b) 500-hPa geopotential heights (dam, solid contours), temperature $\left({ }^{\circ} \mathrm{C}\right.$, dashed contours), and station plot $\left({ }^{\circ} \mathrm{C}\right.$ ) at 1200 UTC 24 January 2015 . Wind in kt (multiply by 0.5144 for $\mathrm{m} \mathrm{s}^{-1}$ ). Images courtesy of SPC (www.spc.noaa.gov/obswx/maps/).

compared with the observed snowfall and predicted orographic ratio from the regression equation to test the utility of the ensemble and the regression equation. This ensemble was chosen because of the high resolution of its members that should have been able to realistically depict the effects of elevation on snowfall across the area. The ensemble forecast indicated snowfall totals of 5-15 cm (4-6 in) across the study area in northeastern Pennsylvania, with the largest amounts in the southern part of the area (Fig. 10). The forecast snowfall did not appear to be dependent on elevation, with lower elevations forecast to receive similar amounts as nearby higher elevations. Some smoothing of the snowfall amounts in the ensemble may have occurred because of combining forecasts from multiple ensemble members; however, the effect of the terrain on snowfall would not be impacted by this smoothing. A NAM model forecast sounding for AVP valid at 0600 UTC 24 January 2015around the middle of the period of observed snowfallindicated a nearly isothermal lower-tropospheric temperature profile, with $900-800-\mathrm{hPa}$ flow from the southwest at 5-10 $\mathrm{m} \mathrm{s}^{-1}(10-20 \mathrm{kt}$, Fig. 11). Values of the 


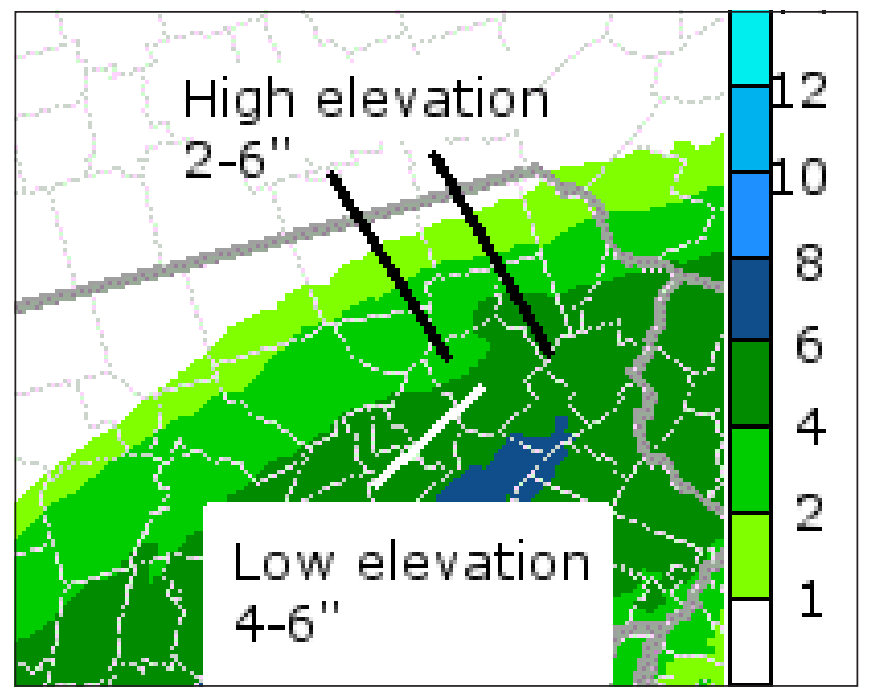

Figure 10. 12-h mean snowfall (in; multiply by 2.54 for $\mathrm{cm}$ ) from the 1200 UTC 23 January 2015 run of the SPC SSEO valid 1200 UTC 24 January 2015.

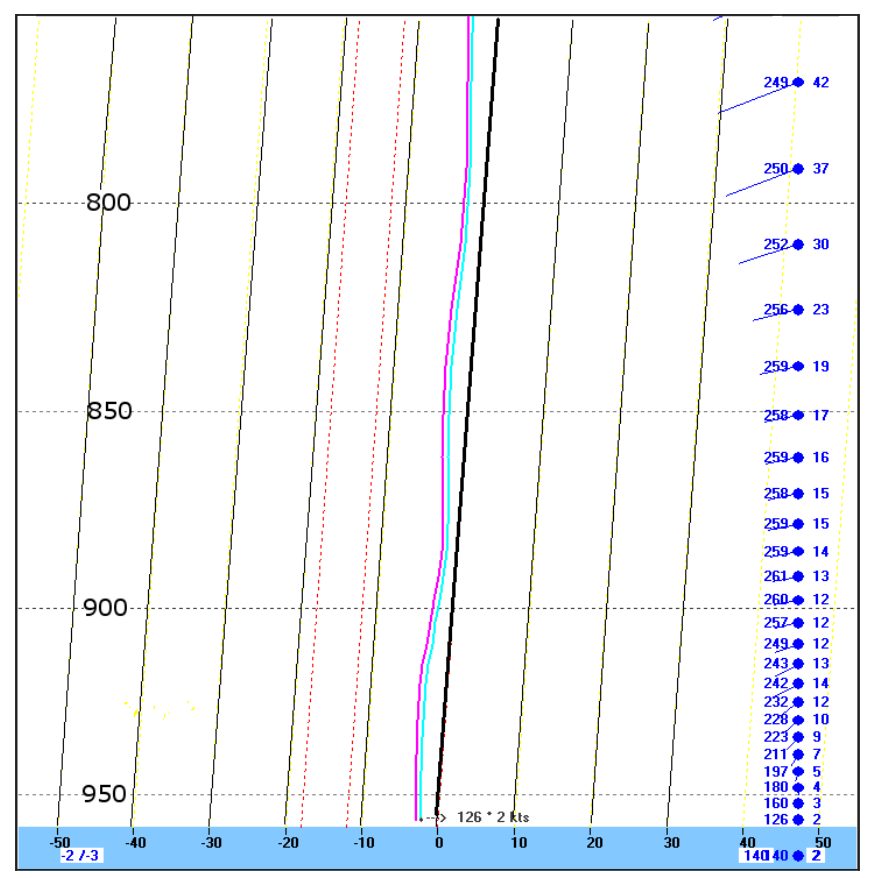

Figure 11. Forecast sounding from the 0000 UTC 24 January 2015 run of the NAM valid at 0600 UTC 24 January 2015 at AVP, displayed using BUFKIT software. The temperature profile is in cyan and the dewpoint profile is in pink. Wind (blue) in kt (multiply by 0.5144 for $\mathrm{m} \mathrm{s}^{-1}$ ).

predictors in the regression equation are shown in Table 4 , along with the predicted orographic ratio as derived from the equation, the observed high-elevation and low-elevation snowfall, and the observed orographic ratio. The equation predicted a ratio of 1.17 , indicating
Table 4. For both case studies (rightmost two columns), values of each predictor in the regression equation are given, along with the predicted high-elevation versus low-elevation snowfall ratio from the regression equation, the observed high-elevation and low-elevation snowfall (using the methods described in section 2), and the observed high-elevation versus low-elevation snowfall ratio.

\begin{tabular}{||l|l|l|}
\hline \hline & 24 January 2015 & 2 February 2015 \\
\hline Time averaged surface temperature $\left({ }^{\circ} \mathrm{C} ;{ }^{\circ} \mathrm{F}\right)\left(\mathrm{x}_{1}\right)$ & $-1.1 ; 30.0$ & $-0.5 ; 31.0$ \\
\hline Time averaged surface wind speed $\left(\mathrm{m} \mathrm{s}^{-1} ; \mathrm{kt}\right)\left(\mathrm{x}_{2}\right)$ & $1.4 ; 2.8$ & $4.1 ; 7.9$ \\
\hline Time averaged 0-1-km wind speed $\left(\mathrm{m} \mathrm{s}^{-1} ; \mathrm{kt}\right)\left(\mathrm{x}_{3}\right)$ & $2.9 ; 5.7$ & $10.5 ; 20.5$ \\
\hline Time-averaged surface / $0-1-\mathrm{km}_{3}$ wind speed $\left(\mathrm{x}_{4}\right)$ & 0.49 & 0.39 \\
\hline Time averaged 0-1-km Brunt-Väisälä frequency $\left(\mathrm{x}_{5}\right)$ & 0.18 & 0.19 \\
\hline Predicted orographic ratio & 1.17 & 1.39 \\
\hline Observed high-elevation snowfall $(\mathrm{cm} ;$ in $)$ & $13.2 ; 5.2$ & $21.3 ; 8.4$ \\
\hline Observed low-elevation snowfall $(\mathrm{cm} ;$ in) & $13.7 ; 5.4$ & $14.0 ; 5.5$ \\
\hline Observed orographic ratio & 0.97 & 1.53 \\
\hline
\end{tabular}

that higher elevations would receive only slightly more snowfall than lower elevations. Observations confirmed that there was little difference between the snowfall at low- versus high-elevations in this case, with lower elevations actually receiving slightly more. In this case, results from the regression equation appeared to confirm the model forecast that elevation would not be a substantial factor in determining snowfall.

\section{February 2015}

A surface low pressure developed near the midAtlantic coast during the morning on 2 February 2015 as a midlevel trough tracked east across the Tennessee Valley (Fig. 12). The surface low was deeper and tracked farther north than in the previous case. Mean snowfall forecasts from the SPC SSEO were 10-15 cm (4-6 in) in the Susquehanna Valley near Wilkes-Barre and 20 $40 \mathrm{~cm}$ (8 to $15 \mathrm{in}$ ) at nearby higher elevations (Fig. 13), which implied an orographic ratio of approximately 2-2.5 and indicated a very substantial impact on snowfall by elevation. A NAM model forecast sounding valid for AVP at 0600 UTC 2 February 2015-around the middle of the period of observed snowfallindicated weak, positive lapse rates in the surface-900$\mathrm{hPa}$ layer, capped by an inversion with weakly negative lapse rates from 900 to $850 \mathrm{hPa}$. Lower-tropospheric winds were from the southeast with speeds ranging from 15 to $21 \mathrm{~m} \mathrm{~s}^{-1}$ (30 to $40 \mathrm{kt}$ ) near ridge-top level, around $900 \mathrm{hPa}$ (Fig. 14). Values of the predictors in the regression equation are shown in Table 4, along with the predicted orographic ratio as derived from the equation, the observed high-elevation snowfall, low-elevation snowfall, and orographic ratio. The equation predicted a ratio of 1.39 , indicating a moderately high-elevation impact on snowfall, but substantially less than what 


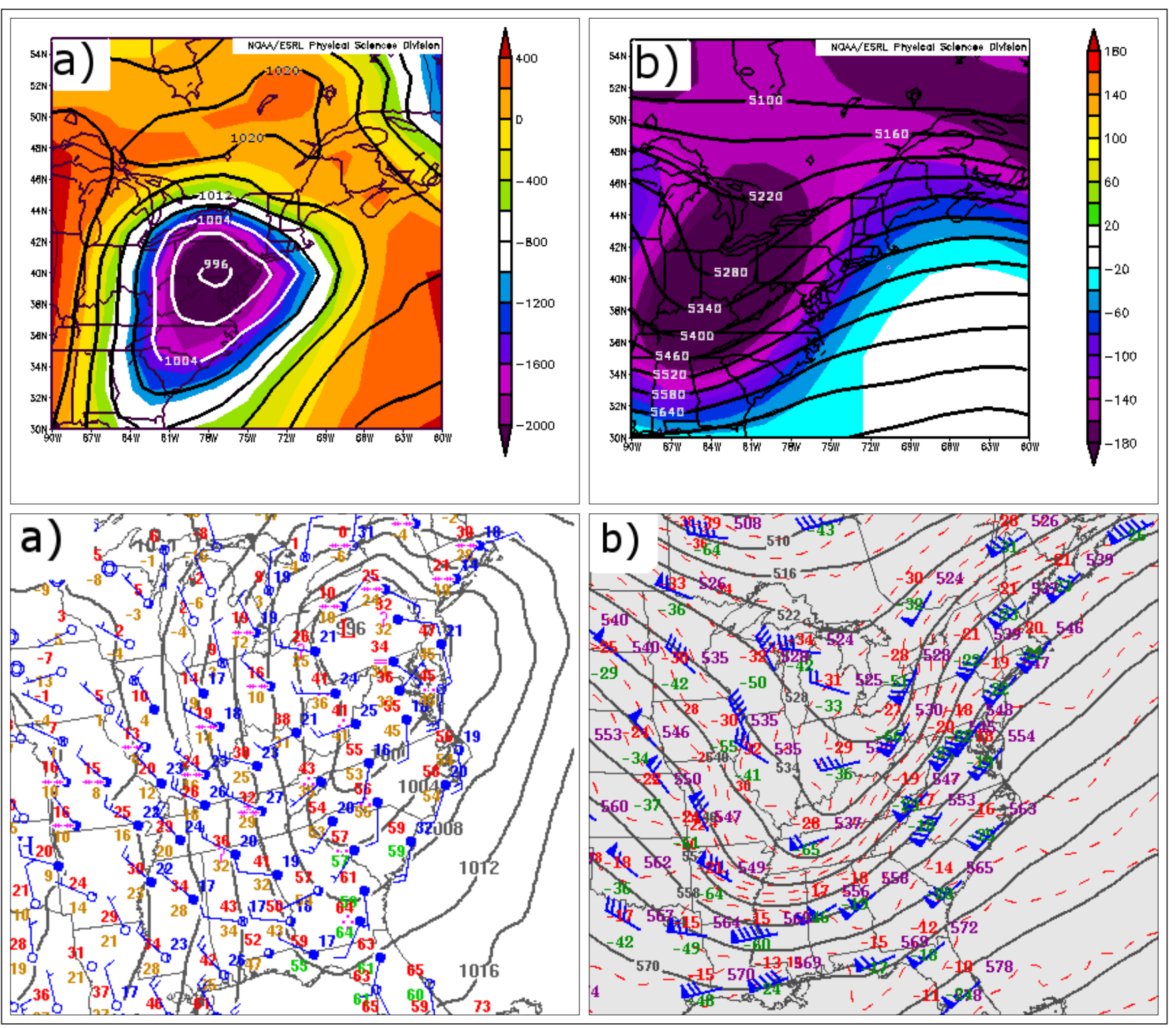

Figure 12. Same as Fig. 9 except valid at 1200 UTC 2 February 2015.

was indicated by the ensemble forecast. Observations indicated a ratio closer to 1.5 , indicating that the equation slightly underforecast the ratio; however, the predicted ratio from the equation was an improvement over what was forecast by the high-resolution ensemble, and certainly could have given a forecaster some indication that the ensemble was overforecasting the impact of elevation on the snowfall.

\section{Summary and discussion}

A study has been described that examines the dependence of snowfall on elevation in the Appalachian Ridge and Valley section of northeastern Pennsylvania.
This work is an extension of a previous study by Evans et al. (2012) that found that the dependence of snowfall on elevation is related to lower-tropospheric wind speed, temperature, and the Froude number. The study described in this paper confirmed the initial findings, and also provided additional details and insights into factors that determine the dependence of snowfall on elevation in northeastern Pennsylvania.

Composite fields and characteristics of the synopticscale flow pattern were examined for the cases in the study in order to give forecasters an idea of patterns to look for when determining the impact of elevation on snowfall. Examination of composite fields for HED events indicated a deep surface low pressure along the 


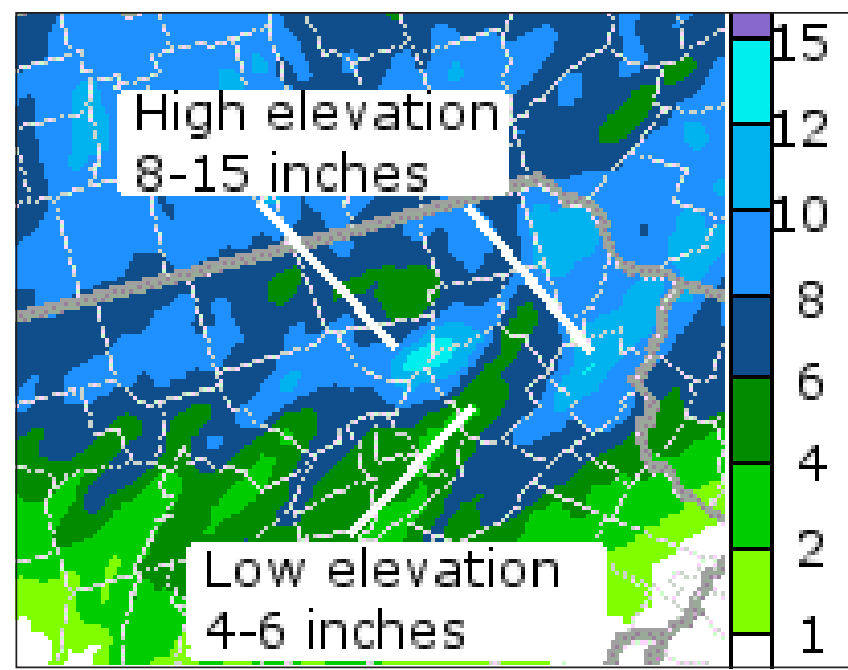

Figure 13. Same as Fig. 10 except for the 1200 UTC 1 February 2015 run valid 1200 UTC 2 February 2015.

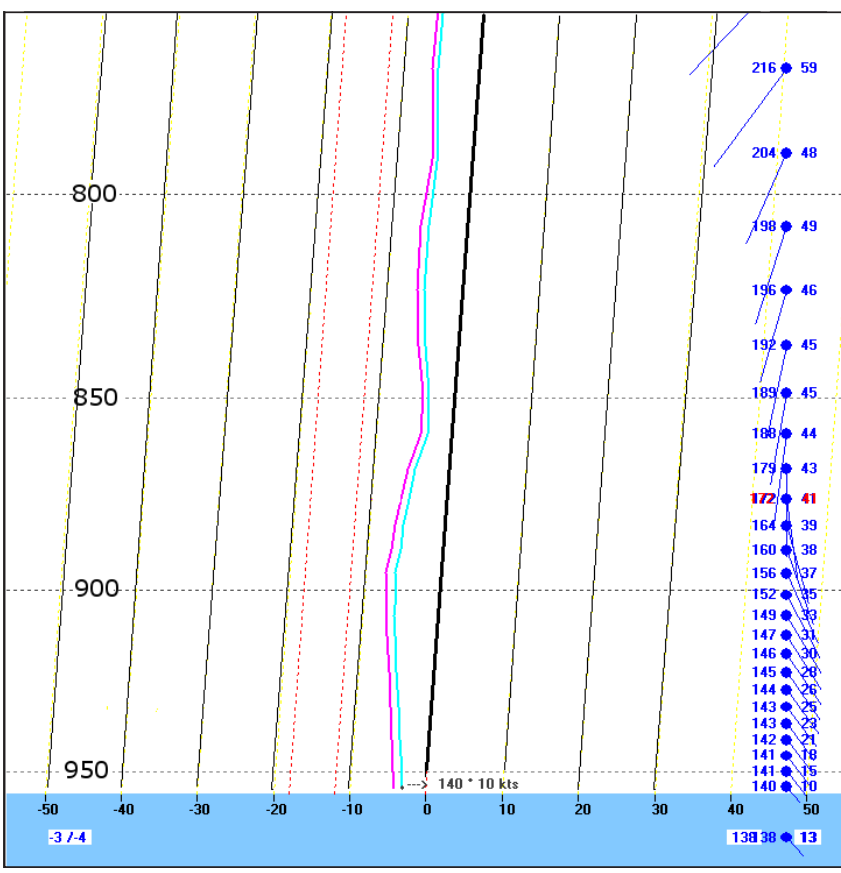

Figure 14. Same as Fig. 11 except for the 0000 UTC 2 February 2015 run valid 0600 UTC 2 February 2015.

East Coast of the United States. Surface high pressure in the composite was located over southeastern Canada. Surface cyclone tracks associated with these cases indicated a disproportionately large number of Miller type A tracks compared to the rest of the dataset, which helps to explain the strong signal for a deep surface low pressure center off the East Coast in the composites. Composites for LED events were characterized by weaker areas of surface low pressure along the East Coast, weaker midtropospheric troughs located farther to the west over the eastern Great Lakes, and a surface high pressure centered farther to the west - north of Lake Superior. The LED cases were dominated by Miller type B storm tracks, which produced a weaker composite signal for the surface low pressure off the coast compared to the HED cases. At $500 \mathrm{hPa}$, the composites indicated deeper troughs closer to the coast for the HED cases, with more amplified downstream ridging. Examination of individual cases indicated that HED events were associated with closed-contoured $500-\mathrm{hPa}$ low centers more often than LED events, which explains the deeper trough in the composite for the HED cases.

A study of several surface and model forecast sounding-based variables associated with the cases indicated that lower-tropospheric wind speed correlated most strongly to the impact of elevation on snowfall, with stronger winds resulting in larger elevation dependence. The strong winds observed in HED events were often associated with well-developed coastal cyclones with Miller type A storm tracks, whereas the lighter winds associated with LED cases were associated with weakening cyclones over the Midwest and newly developed cyclones along the East Coast associated with Miller type B scenarios.

Correlations between surface temperatures and elevation dependence were lower than for wind; however, cases of low dependence were rare when the surface temperature at AVP averaged above $-1^{\circ} \mathrm{C}\left(30^{\circ} \mathrm{F}\right)$. Values of parameters associated with lower-tropospheric lapse rates indicated a small, positive correlation between lapse rate and elevation dependence; however, the correlations were not statistically significant.

The low correlation between the orographic ratio and stability in this study potentially can be explained by the fact that stability is typically rather high for any case in northeastern Pennsylvania featuring significant snowfall amounts. To illustrate this point, consider that the time-averaged surface wind speed at AVP was less than half of the time-averaged $0-1-\mathrm{km}$ wind speed for every case in the study, implying that significant snowfall in northeastern Pennsylvania generally occurred with stable, weakly mixed conditions, regardless of elevation dependence. It is quite likely that stability plays a more substantial role in snowfall elevation dependence in other parts of the country; for example, locations on the west slopes of the Appalachians frequently receive substantial snowfalls in less stable regimes (Keighton et al. 2009) and stability may correlate more strongly with elevation dependence in that area.

Correlations between the Froude number and the 
orographic ratio were only slightly larger than for $0-1$ $\mathrm{km}$ wind and orographic ratio, indicating that for this dataset the wind speed component of the Froude number was a much more significant factor than the stability component. A threshold of around 1.0 was found to be an excellent indicator for whether an event would be characterized as HED or LED. This finding matched results from numerous previous studies indicating that Froude numbers $>1.0$ are associated with winds flowing freely up and over mountain barriers, resulting in upslope and downslope wind components that enhance the dependence of precipitation and snowfall on elevation.

A regression equation based on many of the factors examined in the study was derived to give forecasters an index that would help them to determine elevation impacts on snowfall in northeastern Pennsylvania. Interestingly, some of the factors that were determined to be most appropriate for the equation did not correlate strongly with elevation dependence on their own; however, these variables appear to work in conjunction to provide a meaningful relationship to determine the elevation dependence of snowfall. $\mathrm{R}^{2}$ for the regression equation was 0.53 , which was larger than the $\mathrm{R}^{2}$ for any of the individual predictors, including the Froude number. This implies that the regression equation can provide forecasters with guidance that is superior to examination of any single parameter, including the Froude number. For comparison purposes, an equation was derived where the only predictive factors were Froude number and surface temperature at AVP. The resulting $\mathrm{R}^{2}$ for this equation was only 0.25 , indicating that the primary equation derived in this study provides superior guidance to an equation based only on the Froude number and surface temperature.

Despite the fact that this equation appears to provide superior guidance versus use of the Froude number, or any other single parameter, it must be conceded that one of the primary findings of this study is that predicting the effect of elevation on snowfall for these cases is shown to be quite difficult. Some reasons for this finding could include uncertainty in the quality of the observational data, and also could be related to approximations related to time-averaging the data over the period of the storm. Some calculations were done using parameters derived at times near the midpoint of the storm, at times when precipitation rates were highest; however, preliminary findings did not indicate that this method would result in more satisfactory results.

Finally, forecasters should realize that all model forecasts of wind and temperature in the $0-1-\mathrm{km}$ layer- which are the basis for the regression equation - are subject to errors associated with the model's planetary boundary layer scheme, which can be substantial (Cohen et al. 2015). Given these limitations, forecasters should realize the potential for errors when applying this model-based equation. Forecasters can compare the results from the equation to an analysis of the storm track as a sanity check of the output from the equation, with the idea being that Miller type A storms will typically produce larger orographic ratios than for Miller type B storms. Forecasters also should continuously monitor surface observations to ensure that model forecasts of lower-tropospheric wind and temperature are accurate and will provide reasonable input into the regression equation.

Two case studies were shown to demonstrate the potential utility of the regression equation. The first study was an LED case, and the equation indicted a low dependence of snowfall on elevation, although not quite as low as what was observed. Output from the SPC SSEO also indicated that snowfall in this case would not be substantially impacted by elevation. The second event was a HED case, and the ensemble appeared to dramatically overforecast the elevation dependence for the case. The equation also indicated substantial elevation dependence for this case; however, the dependence was much lower than the model forecast and appeared to better match what was observed. This result implies that output from the regression equation can be used by forecasters to evaluate, and potentially improve upon, forecasts from high-resolution models.

Verification studies of quantitative precipitation forecasts from high-resolution models in complex terrain have found that models often overforecast or underforecast precipitation on the lee or windward slopes of mountain ranges depending on model resolution or physics (Colle and Mass 2000; Mass et al. 2002; Grubišić et al. 2005; Schwitalla et al. 2008). These results indicate that reliance on model output alone may be insufficient for forecasting realistic patterns of snowfall in mountainous areas. The results from this study imply that output from high-resolution models can be improved upon by forecasters who have a physical understanding of the factors and processes that impact snowfall patterns in mountainous terrain.

Forecasters at the NWS Forecast Office at Binghamton, New York (WFO BGM) are currently tasked with producing high-resolution forecasts of snowfall for northeastern Pennsylvania in order to provide decision makers with detailed information on snowfall variations with elevation. Results from this 
study will be used at WFO BGM operationally to aid with these forecasts. The expected procedure will be that forecasters will generate an initial snowfall forecast for the area, and then apply a forecast editing tool that calculates the necessary predictors from model forecasts and determines a snowfall ratio based on the regression equation for the case. The tool will then apply the ratio to the initial forecast at each grid point in the forecast area, with adjustments made to the forecast at each point depending on the point's elevation. These results will be compared to output from high-resolution models and forecaster experience before a final forecast is issued. Because the predictors used by the tool would come from model forecasts, they would be subject to any model errors or biases inherent in the model forecast.

The methods of this study were designed so that it may be applied to the entire ridge and valley region of the Appalachian Mountains. Many of the findings in this study also should apply to areas farther south and west along the Appalachian Mountain chain. However, differences in topography between northeastern Pennsylvania and other portions of the Appalachian Mountains could lead to minor differences in results compared to what was found in this study.

Acknowledgments. The authors thank three anonymous reviewers from the Eastern Region of the NWS along with three anonymous reviewers from the Journal of Operational Meteorology for many helpful comments and suggestions on this manuscript.

\section{REFERENCES}

Alcott, T. I., and W. J. Steenburgh, 2013: Orographic influences on a Great Salt Lake-effect snowstorm. Mon. Wea. Rev., 141, 2432-2450, Crossref.

Bell, G. D., and L. F. Bosart, 1988: Appalachian cold-air damming. Mon. Wea. Rev., 116, 137-161, Crossref.

Bosart, L. F., and D. B. Dean, 1991: The Agnes rainstorm of June 1972: Surface feature evolution culminating in inland storm redevelopment. Wea. Forecasting, 6, 515-537, Crossref.

Brady, R. H., and J. S. Waldstreicher, 2001: Observations of mountain wave-induced precipitation shadows over northeast Pennsylvania. Wea. Forecasting, 16, 281-300, Crossref.

Campbell, L. S., W. J. Steenburgh, P. G. Veals, T. W. Letcher, and J. R. Minder, 2016: Lake-effect mode and precipitation enhancement over the Tug Hill Plateau during OWLeS IOP2b. Mon. Wea. Rev., 144,
1729-1748, Crossref.

Chen, S.-H., Y.-L. Lin, and Z. Zhao, 2008: Effects of unsaturated moist Froude number and orographic aspect ratio on a conditionally unstable flow over a mesoscale mountain. J. Meteor. Soc. Japan, 86, 353-367, Crossref.

Cohen, A. E., S. M. Cavallo, M. C. Coniglio, and H. E. Brooks, 2015: A review of planetary boundary layer parameterization schemes and their sensitivity in simulating southeastern U.S. cold season severe weather environments. Wea. Forecasting, 30, 591-612, Crossref.

Colle, B. A., and C. F. Mass, 2000: The 5-9 February 1996 flooding event over the Pacific Northwest: Sensitivity studies and evaluation of the MM5 precipitation forecasts. Mon. Wea. Rev., 128, 593-617, Crossref.

Durre, I., M. F. Squires, R. S. Vose, X. Yin, A. Arguez, and S. Applequist, 2012: NOAA’s 1981-2010 U.S. Climate Normals: Monthly precipitation, snowfall, and snow depth. J. Appl. Meteor. Climatol., 52, 2377-2395, Crossref.

Evans, M., M. L. Jurewicz Jr., and R. Ballentine, 2012: A preliminary examination of the elevation dependence of snowfall in northeast Pennsylvania. Preprints, 37th Annual Meeting, Madison, WI, Natl. Wea. Assoc., P1.28. [Available online at nwas.org/annual-meetingevents/past-meetings/2012-annual-meeting/.]

Forbes, G. S., R. A. Anthes, and D. W. Thomson, 1987: Synoptic and mesoscale aspects of an Appalachian ice storm associated with cold air damming. Mon. Wea. Rev., 115, 564-591, Crossref.

Gibbons, J. D., 1976: Nonparametric methods for quantitative analysis. American Sciences Press Inc., 463 pp.

Grubišić, V., R. K. Vellore, and A. W. Huggins, 2005: Quantitative precipitation forecasting of wintertime storms in the Sierra Nevada: Sensitivity to the microphysical parameterization and horizontal resolution. Mon. Wea. Rev., 133, 2834-2859, Crossref.

Jirak, I. L., S. J. Weiss, and C. J. Melick, 2012: The SPC Storm-Scale Ensemble of Opportunity: Overview and results from the 2012 Hazardous Weather Testbed Spring Forecasting Experiment. Preprint, 26th Conf. on Severe Local Storms, Nashville, TN, Amer. Meteor. Soc., P9.137. [Available online at ams.confex.com/ a m s / $26 \mathrm{~S} \mathrm{~L} \mathrm{S/w} \mathrm{ebprogram/Manuscript/}$ Paper211729/2012_SLS_SSEO_exabs_Jirak_final.pdf.]

Kalnay, E., and Coauthors, 1996: The NCEP/NCAR 40-year reanalysis project. Bull Amer. Meteor. Soc., 77, 437-471, Crossref.

Keeter, K. K., S. Businger, L. G. Lee, and J. S. Waldstreicher, 1995: Winter weather forecasting throughout the eastern United States. Part III: The effects of topography and the variability of winter weather in the Carolinas and Virginia. Wea. Forecasting, 10, 42-60, Crossref.

Keighton, S., and Coauthors, 2009: A collaborative approach to study northwest flow snow in the southern Appalachians. Bull. Amer. Meteor. Soc., 90, 979-991, 
Crossref.

Mahoney, E. A., and T. A. Niziol, 1997: BUFKIT: A software application toolkit for predicting lake-effect snow. Preprints, 13 th Intl. Conf. on Interactive Information and Processing Systems for Meteorology, Oceanography, and Hydrology. Long Beach, CA, Amer. Meteor. Soc., 388-391.

Mass, C., 1981: Topographically forced convergence in western Washington State. Mon. Wea. Rev., 109, 1335-1347, Crossref.

, D. Ovens, K. Westrick, and B. A. Colle, 2002: Does increasing horizontal resolution produce more skillful forecasts? Bull. Amer. Meteor Soc., 83, 407-430, Crossref.

Miller, J. E., 1946: Cyclogenesis in the Atlantic coastal region of the United States. J. Meteor., 3, 31-44, Crossref.

Muccilli, M., 2015: Using the Froude number to improve orographic snow forecasts in the Green Mountains of Vermont. NOAA/NWS ER Tech. Attach. 2015-05, $43 \mathrm{pp}$. [Available online at www.weather.gov/media/erh/ ta2015-05.pdf.]

O'Hara, B. F., M. L. Kaplan, and S. J. Underwood, 2009: Synoptic climatological analysis of extreme snowfalls in the Sierra Nevada. Wea. Forecasting, 24, 1610-1624, Crossref.

Perry, L. B., C. E. Konrad, and T. W. Schmidlin, 2007: Antecedent upstream air trajectories associated with northwest flow snowfall in the southern Appalachians. Wea. Forecasting, 22, 334-352, Crossref.

Reges, H. W., N. Doesken, J. Turner, N. Newman, A. Bergantino, and Z. Schwalbe, 2016: CoCoRaHS: The evolution and accomplishments of a volunteer rain gauge network. Bull. Amer. Meteor. Soc., 97, 1831-1846, Crossref.

Rogers, E., T. Black, B. Ferrier, Y. Lin, D. Parrish, and G. DiMego, 2001: Changes to the NCEP Meso Eta Analysis and Forecast System: Increase in resolution, new cloud microphysics, modified precipitation assimilation, modified 3DVAR analysis. NOAA / NWS Tech. Procedures Bull. 488, 21 pp. [Available online at http://www.emc.ncep.noaa.gov/mmb/mmbpll/ eta12tpb/.]

Schwitalla, T., H. Bauer, V. Wulfmeyer, and G. Zangl, 2008: Systematic errors of QPF in low-mountain regions as revealed by MM5 simulations. Meteorologische Zeitschrift, 17, 903-919, Crossref.

Steenburgh, W. J., 2003: One hundred inches in one hundred hours: Evolution of a Wasatch Mountain winter storm cycle. Wea. Forecasting, 18, 1018-1036, Crossref.

Wesley, D. A., G. Poulos, J. Snook, P. Kennedy, M. Meyers, and G. Byrd, 2013: Extreme snowfall variations and cold-air damming in the Front Range heavy snowstorm of 17-19 March 2003. J. Operational Meteor., 1 (4), 26-51, Crossref. 